\title{
Arnaldo Angelucci †
}

Am 30. November 1933 entschlief in Neapel, hochbetagt, Arnaldo Angelucci, der langjährige Vorstand der dortigen Universitätsaugen-klinik, ein Großer in unserer Wissenschaft. Im April 1854 in Subiaco bei Rom geboren, genoß er nach Be-endigung des medizinischen Studiums bei Zehender, Ranvier, Javal, Charcot, namentlich aber beim Physiologen Boll in Rom seine Aus-bildung; so schenkte er auch in späteren Jahren der Physiologie des Sehorgans besonderes Interesse. Schon mit 31 Jahren wurde er ordent-licher Professor in Cagliari, folgte bald darauf dem Rufe nach Messina und später nach Palermo, wo er 16 Jahre lang als hochgeschätzter Lehrer wirkte. Als im Jahre 1905 durch den Tod De Vincentiis, des großen Erneuerers der Augenheilkunde in Italien, die Augenklinik der parthenopäischen Universität verwaist ward, fiel,die Wahl auf Angelucci, der die ehrenvolle Berufung annahm und bis zur Erreichung der Alters-grenze (1929) mit besonderer Hingabe und Eifer seiner Pflicht als Lehrer und wissenschaftlicher Forscher oblag.

Sein großes Lebenswerk zeugt von seiner schöpferischen Geisteskraft, von seiner vielseitigen Bildung und von seiner angeborenen Befähigung, biologische Probleme vom rechten Gesichtspunkt aus gründlich anzu-gehen. Auch verstand er es vorzüglich, die Jugend zu neuer uud nütz-licher Arbeit anzuregen. Zahllos sind seine Schüler in der Ärzteschaft Italiens und seinem Vorbilde folgend, haben sich mehrere von ihnen wissenschaftlich in solchem Maße hervorgetan, daß es ihnen vergönnt ist, als ordentliche Professoren der Augenheilkunde die Lehren des Meisters zu verbreiten und das Ansehen seiner Schule in Ehren zu halten. Wie gesagt, fühlte sich A ngelucci zu physiologischen Fragen beson-ders hingezogen: seine Arbeiten über den Mechanismus des Sehaktes sind bahnbrechend; ihnen verdanken wir unsere Kenntnisse über die morphologischen und chemischen Vorgänge in der Netzhaut und den Sehbahnen nach Belichtung des Auges; die Ergebnisse seiner eigenen Untersuchungen und jener seiner Schüler führten zur Aufstellung einer neuen Lehre vom Sehen. Nicht unerwähnt dürfen Angeluccis Studien bleiben, welche das Verhältnis des Halssympathikus zum Auge behan-deln, sowie seine experimentellen Untersuchungen über die Bildung des Kammerwassers und über die Ernährung des Auges. - Aber auch der Pathologie und Klinik der Augenkrankheiten widmete er sich mit

$\neq$

Arnaldo Angelucci $\uparrow$.

großem Fleiße und klarem Blicke: ihm gebührt das Verdienst, schon im Jahre 1881 auf die Beziehungen zwischen Gefäßveränderungen und iglaukomatösen Symptomen hingewiesen zu haben. Nie hat er den Zu-sammenhang der speziellen Pathologie des Auges mit der gesamten Heilkunde verloren: er stellte fest, daß Menschen, welche an Frühjahrs-katarrh leiden, eigentümliche Begleiterscheinungen aufweisen (reizbare Gemütsart, Hitze im Gesicht, nervöses Herzklopfen), welche auf neuro-endokrinen Störungen beruhen; dieser Symptomenkomplex führt den Namen des Meisters. In den letzten Dezennien seines arbeitsvollen Lebens beschäftigte er sich gerne mit der Konstitutionslehre und lenkte das Augenmerk der Pfleger unserer Fachwissenschaft auf die konsti-tutionelle Pathologie. So schrieb er z. B. in der Pathogenese des 
Tra-choms der Körperbeschaffenheit eine große Rolle zu und behauptete, daß zwischen Trachom und Adenoidismus gewisse Beziehungen bestehen, Beziehungen, die dann zu neuen Anschauungen in therapeutischer und prophylaktischer Hinsicht führten. - Aber auch die Chirurgie wurde von ihm durch neue, äußerst sinnreiche Eingriffe bereichert: seine Ektropionund Ptosisoperationen werden überall ausgeführt und gelehrt, von ihm stammt die Bulbusfixation durch Fassen des M. rectus superior, ein Verfahren, das später zur Zügelnaht führte. Besondere Liebe empfand A ngelucci für die Kunst; als feiner Kunst-kenner und Kunstbeflissener ward ihm als Stadtverordneter die Ober-aufsicht über alle Kunstdenkmäler der Stadt Neapel übertragen, ein Amt, das er lange Jahre hindurch zu seiner großen Freude und Genugtuung inne hatte; er selbst besaß eine sehenswürdige Sammlung von Bildern iarbenuntüchtiger Maler und hat gar manches über schöne Künste ge-schrieben; von seiner künstlerischen Veranlagung und seinem sprühen-den Geiste legen zwei bedeutende Arbeiten Zeugnis ab (, ,Das Sehen in der Kunst und die Kunst im Mechanismus des Lebens”- ,, Psychoanalyse und Sublimation in der Kunst").

Im Jahre 1893 gründete er das ,,Archivio di Ottalmologia”, eine in Italien und im Auslande viel gelesene Zeitschrift, welche hoffentlich nach seinem Ableben von unserem Büchertisch nicht verschwinden wird.

Dieser Mann von hervorragenden Geistesgaben, von ungewöhlicher Tatkraft und Arbeitsfreudigkeit war auch ein Heifer in der Not: er stiftete Stipendien für Mediziner und junge Ärzte, die sich unserer Fachwissenschaft widmen und bedachte das Krankenhaus seiner Vaterstadt mit einer größeren Geldsumme.

Von Schülern und Kollegen stets geliebt, war er von alien jenen, -die ihn besser kannten, hochgeschätzt und bewundert, denn er war ein herzensguter, vertrauenseliger Mensch, in dessen Nähe man sich wohlfühlte. Zum letzten Male sahen wir ihn in Amsterdam beim internationalen Kongresse, wo er in liebenswürdiger und geistreicher Weise nicht nur •an den wissenschaftlichen Sitzungen, sondern auch an den geselligen Veranstaltungen mit gesundem Humor und frischer Lebensauffassung regen Anteil genommen hatte.

D. Dem Meister, der sich einer internationalen Schätzung und Beliebt-heit erfreute, werden wir ein treues und ehrendes Andenken bewahren.

Oblath (Trieste). 